Bull. Pharm. Sci., Assiut University

Vol. 12, Part 1, pp $117=124$

\title{
SAPONINS FROM ZYGOPHYLLUM ALBUM L.
}

\author{
H.A.Hasanean, M.A.El-Shanawany, D.W.Bishay and G.Franz* \\ Department of PHarmacognosy, Faculty of Pharmacy, \\ Assiut University, Assiut, Egypt. \\ * Fakultat Chemie/Pharmazie, Universitat Regensburg, \\ Regensburg, West Germany.
}

\section{ABSTRACT}

Four saponins were isolated from the overground parts of Z. album L. along with B-sitosterol-B-D-glucopyranoside. Their structures were identified as 14decarboxyquinovic acid-0-(3-1)- $\alpha-L$ - rhamnopyranoside (1), quinovic acid- $(28 \rightarrow 1)-\alpha-L-r h a m n o p y r a n o s y l$ ester

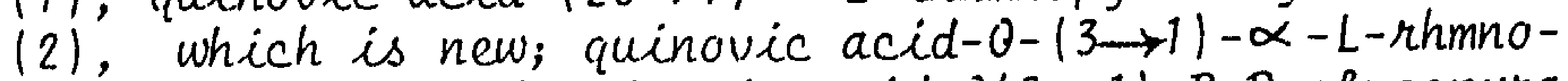
pyranoside (3) and quinovic acid-O(3-1)-B-D-glucopyranoside (4). This identification was based on chemical studies. Glc, Gc/Ms and Mass spectral analysis.

\section{INTRODUCTION}

Zygóphyllum album $L$. is a wild salty desert herb belonging to the family zygophyllaceae ${ }^{l}$. The plant is characterized by containing tritexpene saponins and producing toxic symptoms to domestic animals ${ }^{2}$. $\underline{Z}$. album is known by Egyptian farmers as "Biz El-Kalba".

Hylands.P.J. et $\underline{a l}^{3}$ isolated quinovic acid from $\underline{\mathrm{z}} \cdot \underline{\mathrm{a} l \mathrm{lb}} \mathrm{um}$ L. and the ${ }^{13} \mathrm{C}-\mathrm{NMR}$ of its acetate and dimethylacetate were assigned.

The present work represents the isolation and identification of triterpenoia saponins with particular interest to the study of their sugar moieties. 


\section{8 \\ EXPERIMENTAL \\ H.A.Hasanean et al}

Materials

Z. album L. was collected from the Red sea coastal region near Marsa Alam City in May 1985. Its identification was confiermed by Prof. Dr. M.N.El-Hadidy, Professor of Taxonomy, Dept. of Botany, Faculty of science, Cairo university.

Melting points were determined by an electrothermal appratus and were uncorrected. GLC analysis was performed on Varian 3300. WCOT column' $(0.25 \mathrm{~mm} / 25 \mathrm{~m})$. Carrier gas is nitrogen $(0.8 \mathrm{ml} / \mathrm{min}$. Split : 1:20). Temperature programme of $175-205^{\circ} \mathrm{C}\left(1^{\circ} \mathrm{C} / \mathrm{min}\right)$ and $15 \mathrm{~min}$ isothermal. Detector FID. GC/MS analysis was carried out on Hewlett-packard GC 5890 A coupled with selective mass detector 5970 B and HP work station 300; carrier gas, helium $(0.8 \mathrm{ml} / \mathrm{min}$. split $=1: 50) ;$ Column, Durabond fused silica $(0.25 \mathrm{~mm} / 30 \mathrm{~m}) \mathrm{DB} 170 \mathrm{l}-30 \mathrm{~W}, 25$ um thickness; Temperature, programme 170$210^{\circ} \mathrm{C}\left(1{ }^{\circ} \mathrm{C} / \mathrm{min}\right)$ and $210^{\circ} \mathrm{C}(10 \mathrm{~min}$, isothermal). EIMS was carried out at $70 \mathrm{eV}$ with direct inlet technique.

TLC : Silica gel precoated plates (E.Merck).

system : a) $\mathrm{CHCl}_{3}-\mathrm{MeOH} \quad(90: 10)$.

b) $\mathrm{CHCl}_{3}-\mathrm{MeOH} \quad(85: 15)$.

spots visualized with $40 \% \mathrm{H}_{2} \mathrm{SO}_{4}$ in $\mathrm{MeOH}$, then heated at $130^{\circ} \mathrm{C}$ for $10 \mathrm{~min}$. CC : silica gel (60 - 120 mesh; E. Merck).

Reference materials :

Authentic B-sitosterol-B-D-glucoside and quinovic acid were kindly supplied by Prof. Dr. D. Bishay, Dept. of Pharmacognosy, Faculty of Pharmacy, Assiut University, Assiut, Egypt.

\section{Isolation of saponins :}

The air-dried powdered plant ( $1 \mathrm{Kg}$ ) was macerated on cold with alcohol $70 \%$. The extract $(6 \mathrm{~L})$ was concentrated under vacuum to syrupy consistancy. Then diluted with water (l L) and successively extracted with chloroform and $\mathrm{n}$-butanol. The concentrated n-butanol extract (15 g) was 
chromatographed over silica gel column. Elution was started with $\mathrm{CHCl}_{3}{ }^{-}$ MeOH-H $20(95: 1: 0.1)$ and the polarity was increased gradual1y. Fraction were collected ( $250 \mathrm{ml}$ each) and tested by TLC. Fractions containing similar single spots:were pooled and purified. 'rhis resulted in the isolation and identification of five glycosides labelled $\mathrm{ZS}_{1}-\mathrm{ZS}_{5}$.

Acid hydrolysis :

Each saponin ( $5 \mathrm{mg}$ ) was separately dissolved in 2M TFA (trifluoroacetic acid) in a sealed tube and autoclaved at $120^{\circ} \mathrm{C} / 1$ bar for one hour. TFA was removed by distillation under vacuum and the residue obtained was extracted with $1 \mathrm{ml}$ distilled demineralized water. The obtained aqueous extract was directed to the study of sugars. The water insoluble residue was dissolved in $\mathrm{MeOH}$ and left for crystallization to give the aglycone.

Alkaline hydrolysis ${ }^{4}:$

Each saponin (5 mg) was separately hydrolyzed with $5 \mathrm{~N} \mathrm{NH}_{4} \mathrm{OH}$ in a sealed tube by autoclaving at $120^{\circ} \mathrm{C} / 1$ bar for 3 hours. The sample was neutralized with dil.acetic acid and then lyophilized and worked up as mentioned under acid hydrolysis.

\section{Alditol acetates :}

All alditol acetates were separately prepared following the method of Blackeny, et ${ }^{5}{ }^{5}$. The aqueous hydrolysate of each compound was reduced by $1 \mathrm{ml}$ of $2 \% \mathrm{NaBH}_{4}$ in $0.1 \mathrm{ml} \mathrm{IN} \mathrm{NH}_{3}$ at $60^{\circ} \mathrm{C}$ for $90 \mathrm{~min}$. Acetylation was performed with $2 \mathrm{ml}$ acetic anhydride and $0.2 \mathrm{ml} 1$-methyl imidazole as catalyst.

\section{Partially acetylated methylated sugar :}

Following Harris et al $^{6}$ each saponin (10 mg) was dissolved in DMSO and $0.4 \mathrm{ml}$ of dimethylsulphenyl carbanion was added in an argon atmosphere and left for 2 hours at room temperature with stirring. $0.3 \mathrm{ml}$ methyl iodide was added on cooling then left for one hour. The obtained methylated saponin was diluted with distilled water and extracted with chloroform. The chloroform extract was evaporated under nitrogen atmosphere. Complete methylation was checked by IR and the obtained residue was then hydrolysed and the alditol acetates were prepared as mentioned above. 


\section{RESULTS AND DISCUSSION}

Compound zS : was obtained from CC-fractions (2-4) eluted with $\mathrm{CHCl}_{3}-\mathrm{MeOH}_{2} \mathrm{O}$ (95:1:0.1). It occurs as needle crystals $(500 \mathrm{mg})(\mathrm{MeOH}), \mathrm{mp} 265-67^{\circ} \mathrm{C}, \mathrm{R}_{\mathrm{f}} 0.65$ (system a). It was identified as B-sitosterol-B-D-glucoside by direct comparison with authentic material (mp, mmp, $\mathrm{R}_{\mathrm{f}}$ ) and reported mass spectrum ${ }^{2}$.

Compound $\mathrm{ZS}_{2}(1)$ : subsequen.t elution with the same solvent mixture (fraction $5^{5-8}$ and crystallization from methanol afforded compound $z_{2}$ as needle crystals ( $25 \mathrm{mg}$ ) $\cdot \mathrm{R}_{\mathrm{f}} \mathrm{O} .60$ (system a) Ms, $\mathrm{M}^{+} 442, \mathrm{~m} / \mathrm{z} 427$ $\left(\mathrm{M}^{+}-\mathrm{Me}\right), 409\left(\mathrm{M}^{+}-\mathrm{H}_{2} \mathrm{O}\right), 234$ for retro-Diels Alder fragment $\left[\mathrm{C}_{15} \mathrm{H}_{26}{ }^{\mathrm{O}}\right]^{+}$of norreiterpene having a COOH-group at ring $\mathrm{D}$ or $\mathrm{E}^{7}$, a fragment peak at $\mathrm{m} / \mathrm{z} 207\left[\mathrm{C}_{14} \mathrm{H}_{23} \mathrm{O}\right]^{+}$suggesting the presence of OH-group at the usual $\mathrm{C}_{-}$position $^{8}$ and a peak at $\mathrm{m} / \mathrm{z} 189$ for subsequent loss of $\mathrm{H}_{2} \mathrm{O}$. These results are in good agreement with those reported for 14-decarboxyquinovic acid (27-nor-methylursolic acid) ${ }^{9}$.

In order to determine the linkage and number of sugar units in $\mathrm{ZS}_{2}$, it was subjected to permethylation by Harris et $\underline{\text { al }}$ method ${ }^{6}$. The permethylated glycoside was hydrolysed with acid and the resulting partially methylated sugar was identified by GLC and GC/MS analysis of its alditol acetate as 1,5-di-o-acetyl-2,3,4-o-trimethyl-rhamnose ( $\left.\mathrm{R}_{t} 7.99 \mathrm{~min}\right)$ having the following majn fragments $\mathrm{m} / \mathrm{z} 175(8 \%), 161(27 \%), 131(77 \%), 117(64 \%), 115(50 \%), 101(100 \%), 89$ $(60 \%)$ and $72(25 \%)^{10}$.

The alkaline hydrolysis did not affect the glycoside indicating ether linked rhamnose. Therefore, saponin zs proved to be

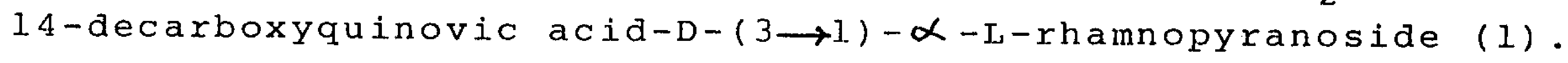

This compound was previously identified in z-coccenium based on quantitative acid hydrolysis ${ }^{9}$.

Compound $\mathrm{ZS}_{3}(2)$ : obtained from fractions. $(10,11)$ eluted

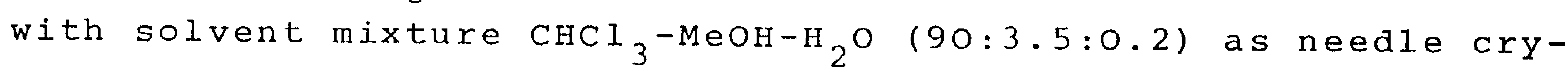
stals $(\mathrm{MeOH})(30 \mathrm{mg}), \mathrm{R}_{\mathrm{f}} 0.50$ (system b). 
The sugar moiety : GLC of the alditol acetate of the aqueous extract of the hydrolysate revealed the presence of D-glucose $\left(R_{t} 22.32 \mathrm{~min}\right)$. GC/MS showed that the suger linked through its $\mathrm{C}_{-1}$ with the aglycone and gave the fragments $\mathrm{m} / \mathrm{z} 205$ $(23 \%), 161(62 \%), 145(57 \%), 129(66 \%), 117(62 \%), 113(14 \%), 101$ $(100 \%), 88(22 \%), 87(37 \%), 71(25 \%)$ and $45(73 \%)$.

The alkaline hydrolysis did not affect the glucoside indicating the presence of ether linkage. Consequently the glucoside $\mathrm{ZS}_{5}$ was elucidated as quinovic acid-O- $(2 \rightarrow 1)-\mathrm{B}-\mathrm{D}-\mathrm{glucopy}-$ ranoside.

This compound is reported for the first time in zygophyllaceae and reported before in family Rubiaceae ${ }^{12,13}$.

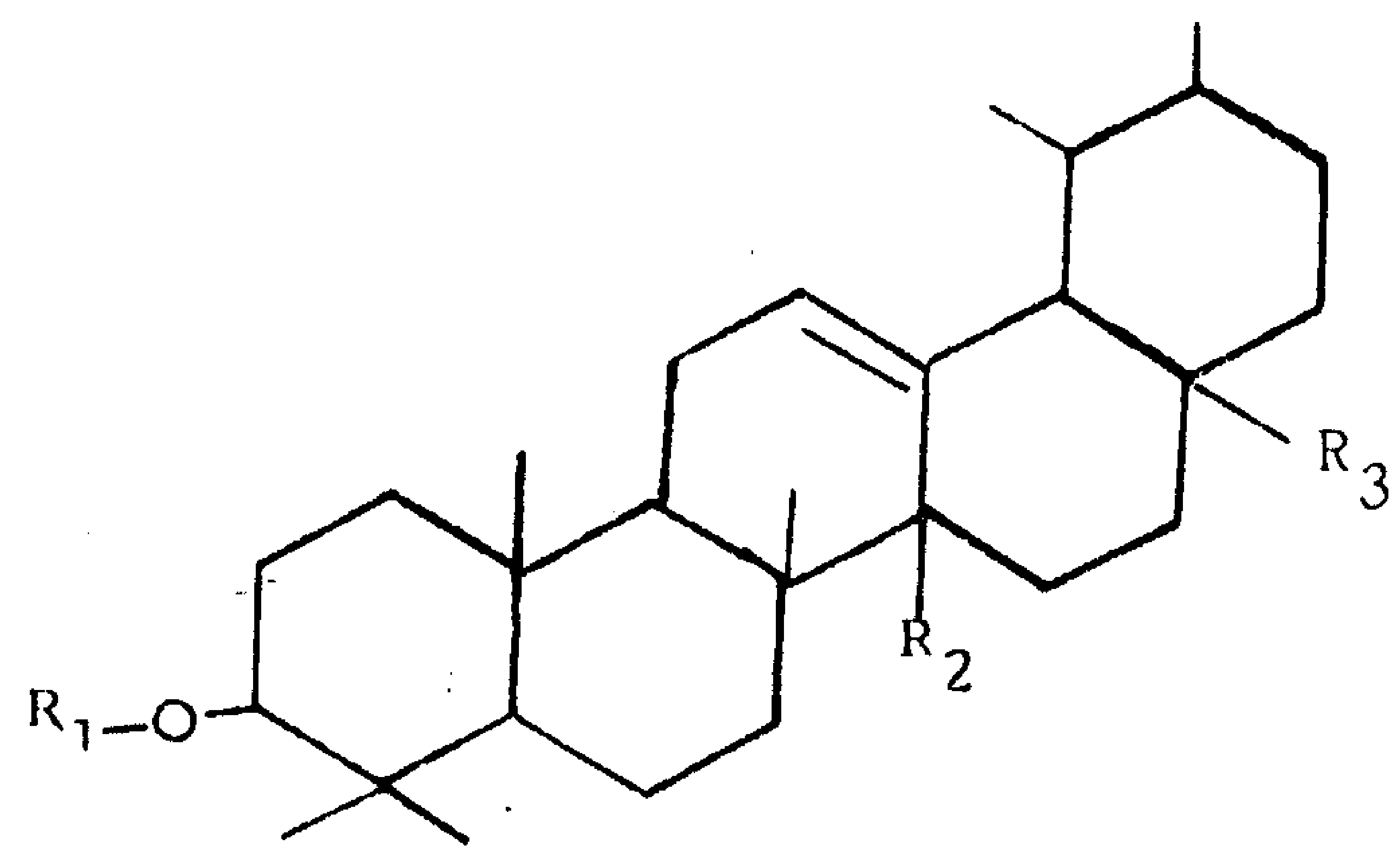

Compound

$Z S_{2}(1)$

$2 S_{3}(2)$

$2.5_{4}(3)$

L-rhamnopyranoside
$R_{1}$

L-rhamnopyranoside

$\mathrm{H}$

$\mathrm{COOH} \quad \mathrm{COOH}$ with either $R_{2}$ or $R_{3}$ )

$\mathrm{COOH} \quad \mathrm{COOH}$
B-D-glucoside
$2 S_{5}(4)$
$\mathrm{COOH}$
$\mathrm{COOH}$ 
The aglycone of compound $\mathrm{ZS}_{3}$ was isolated after acid hydrolysis and proved to be quinovic acid by direct comparison with authentic sample $\left(R_{f}, m p\right.$ and $\left.m m p\right)$ and reported data ${ }^{9}$.

The sugar moiety on GLC and GC/MS analysis of the alditol acetate of the aqueous hydrolysate of compound $\mathrm{zs}_{3}$ revealed the presence of one mole of L-rhammose.

The alkaline hydrolysis showed that rhamnose was cleaved indicating that it is linked to the aglycone through ester linkage.

The above mentioned date proved that glycoside $\mathrm{ZS}_{3}$ is a quinovic acid [28 or $27 \rightarrow 1]-\alpha-r-r h a m n o p y r a n o s y l$ ester. To the best of our knowledge, , this compouna was not previously isolated or reported.

Compound $\mathrm{zS}_{4}(3)$ : obtained from fractions (6-10) eluted with $\mathrm{CHCl}_{3}-\mathrm{MeOH}-\mathrm{H}_{2} \mathrm{O}(9 \mathrm{O}: 3.5: 0.2)$ as needle crystals (MeOH) (4O $\mathrm{mg}), \mathrm{R}_{\mathrm{f}} 0.45$ (system b).

The glycoside $\mathrm{ZS}_{4}$ was similar to glycoside $\mathrm{ZS}_{3}$. but differs in alkaline hydrolysis i.e. $\mathrm{ZS}_{4}$ was not affected indicating that the sugar moiety(L-rhamnose) linked with the aglycone (quinovic acid) through ether linkage. Therefore glycoside $\mathrm{ZS}_{4}$ is quinovic acid-O- $(3 \rightarrow 1)-\alpha$-L-rhamnopyranoside.

This represents the first report for isolation of this glycoside from the family zygophyllaceae but was reported in Rublaceaell.

Compound $\mathrm{ZS}_{5}(4)$ : fractions $(11-16)$ eluted from CC with the same solvent on crystallization from methanol afforded needle crystals $(40 \mathrm{mg}), \mathrm{R}_{\mathrm{f}} 0.41$ (system b).

Acid hydrolysis of compound $\mathrm{ZS}_{5}$ furnished an aglycone and a sugar. The aglycone was found to be the same as that obtained from glycoside $\mathrm{zS}_{4}$ (quinovic acid) on the bases of $\mathrm{R}_{f} \cdot \mathrm{mp}$. $\mathrm{mmp}$ and MS. 
Saponins From Zygophyllum Album L.

\section{REFERENCES}

1) V.Tackholm, "Student Flora of Egypt", 2nd Ed., Cairo. University, 300
(1974).

2) A.M.El-Moghazy; D.W.Bishay, S.A.Ross; J. African Medicinal Plants, in
Press.

3) P.J.Hylands, S.A.Ross, M.M.El-hammouly and M.S.Maged, Al-Azhar J.Nat. Prod., Al-Azhar Universitel, 2,

4) V.Hariharan and S.Rahgaswami, Phytochemistry, 9, 409 (1970).

5) A.B.Blackeny, P.G.Harris, R.J.Henry and B.A.Stone, Carbohydrate. Res.,
$113,291(1983)$.

6) P.G. Harris, R.J.Henry, A.B.Blackeny and B.A.Stone, Carbohydrate. Res.,
$127,59(1984)$.

7) C.Djerrassi, H.Bud Zikiewicz and J.M.Wilson, Tetrahedron Letters. 263
(1962).

8) R.Ranaka, M.Tabuse and S.Matsunaga; Phytochemistry., 3563 (1988).

9) A.A.Attia, "Phytochemical Study of Both Jasminium mesnyi H. and Zygophyllum coccenium L. growing in Egypt". Ph.D. Thesis. Assiut University, Assiut. Egypt. (1986).

10) H.Bjorndal, B.Lindberg and S. Suenson, Carbohydrate Res., 15, 339(1970).

11) R.F.Raffuf, P.W.Le Chvesne and P.C.Ghosh, Lloydia, 41, 432 (1978).

12) M.E.O.Matos, M.P.Sousa, and R.Braz, Phytochemistry, 25, 1419 (1986).

13) R.Tscheche, I.Duphorm and G.Snatzke, Liebigs Ann., 151,667 (1963). 
مابونينـات من نبـات زيجوفيللبوم ابيـــــل

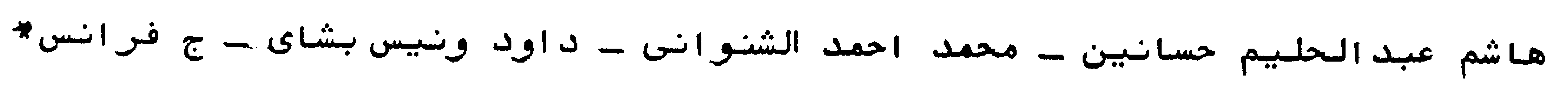

قسم العقاقير ـ كلية الصيدلـة ـ جامعة اسيوط ومعهد الكيميـء والصيدلة - جبامعـــــة

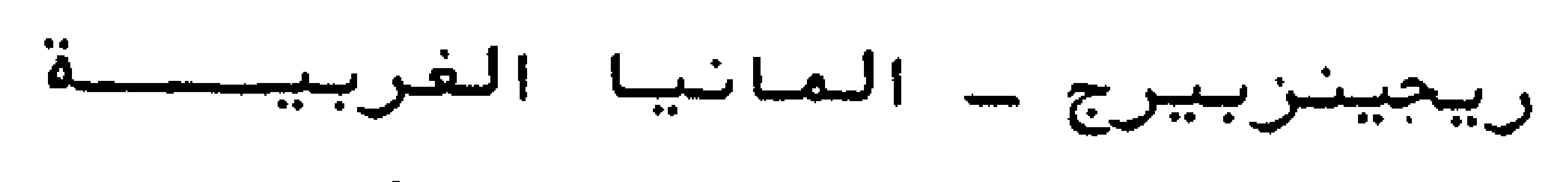

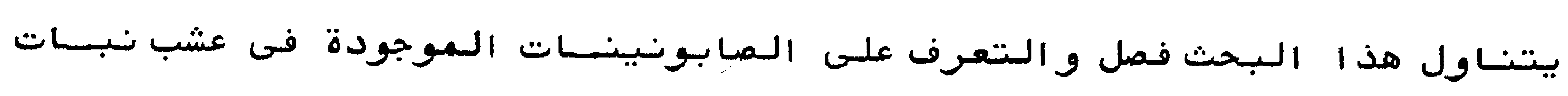

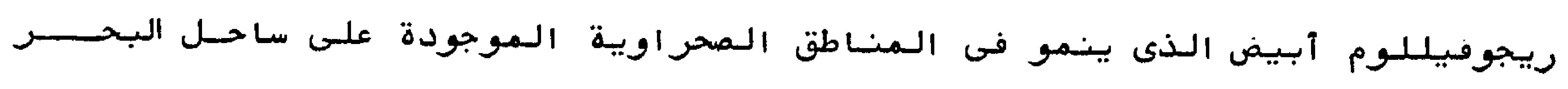
الأحمر بالغرب من مدينة مرسى علم • وتـم فى هذا الـبحث التعرف على خمس مركبـــات

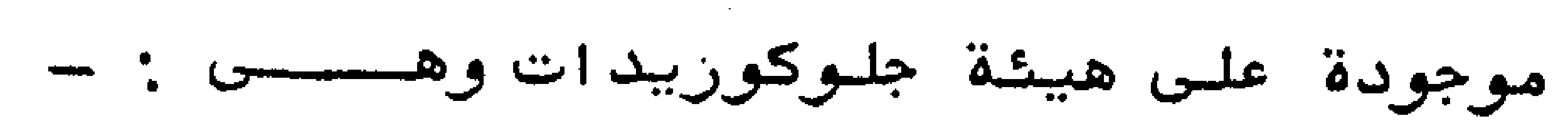
1 • -

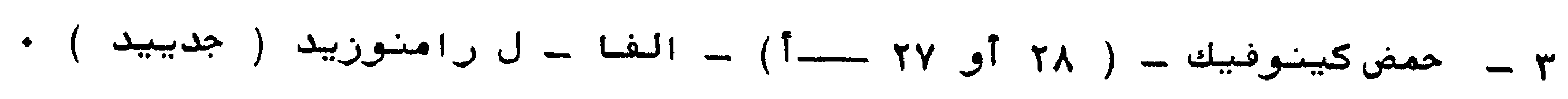
ع - حمض كينوفيك - آ- (

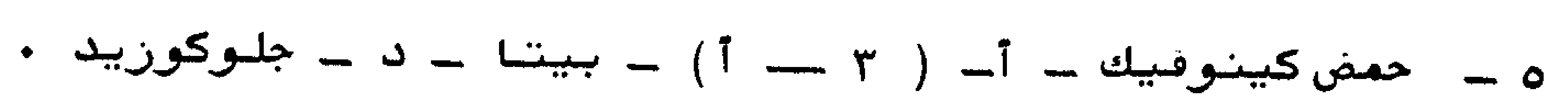

وأستخدمت الطرق المختلـفة لـفمل والتتعرف على هذه الـمواد مثل كرومـاتوجر افيب

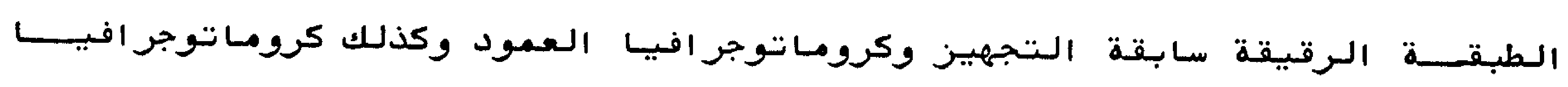

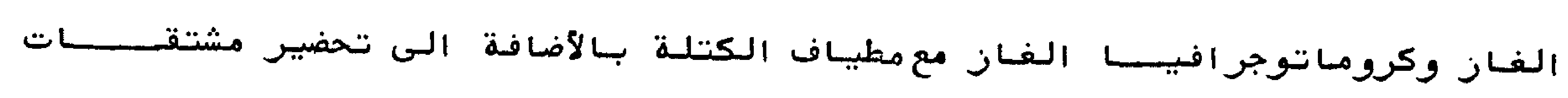

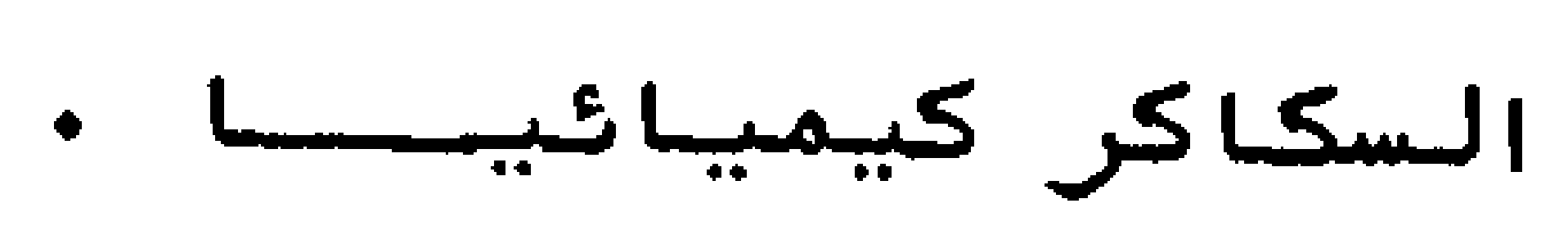

received in $18 / 2 / 1989$ \& accepted in $28 / 5 / 1989$ 